\title{
Reactions of Aluminium(I) with Transition Metal Carbonyls: Scope, Mechanism and Selectivity of CO Homologation
}

\author{
Richard Y. Kong, Maria Batuecas, and Mark R. Crimmin* \\ Department of Chemistry, Molecular Sciences Research Hub, Imperial College London, 82 Wood Lane, \\ Shepherds Bush, London, W12 OBZ, UK.
}

\begin{abstract}
$\underline{\text { Abstract }}$
Over the past few decades, numerous model systems have been discovered that create carbon-carbon bonds from CO. These reactions are of potential relevance to the Fischer-Tropsch (F-T) process, a technology that converts syngas mixtures $\left(\mathrm{H}_{2} / \mathrm{CO}\right)$ into mixtures of hydrocarbons. In this paper, a new homogeneous model system that constructs carbon chains from $\mathrm{CO}$ is reported. The system exploits the cooperative effect of a transition metal complex and main group reductant. An entire reaction sequence from $C_{1} \rightarrow C_{2} \rightarrow C_{3} \rightarrow C_{4}$ has been synthetically verified. The scope of reactivity is broad and includes a variety of transition metals ( $M$ $=\mathrm{Cr}, \mathrm{Mo}, \mathrm{W}, \mathrm{Mn}, \mathrm{Re}, \mathrm{Co})$, including those found in industrial heterogeneous F-T catalysts. Variation of the transition metal fragment impacts the relative rate of the steps of chain growth, allowing isolation and structural characterisation of a rare $C_{2}$ intermediate. The selectivity of carbon chain growth is also impacted by this variable; two distinct isomers of the $C_{3}$ carbon chain were observed to form in different ratios with different transition metal reagents. Based on a combination of experiments (isotope labelling studies, study of intermediates) and calculations (DFT, NBO, ETS-NOCV) we propose a complete mechanism for chain growth that involves defined reactivity at both transition metal and main group centres.
\end{abstract}

\section{Introduction}

Chemical reactions that allow the formation of useful fine chemicals from $\mathrm{C}_{1}$ building blocks such as $\mathrm{CO}$ or $\mathrm{CO}_{2}$ are of contemporary interest. ${ }^{1}$ These reactions hold promise for sustainable chemical manufacturing methods, as $\mathrm{CO}$ can be obtained from renewable sources including biomass. ${ }^{2,3}$ One approach that has a long history is the Fischer-Tropsch (F-T) reaction. Executed on large scales and mediated by heterogeneous transition metal catalysts (typically cobalt, iron, ruthenium), the Fischer-Tropsch process (eq. 1) allows access to mixtures of hydrocarbons with an Anderson-Schulz-Flory distribution from $\mathrm{CO}$ and $\mathrm{H}_{2}{ }^{4}$

$$
(n) \mathrm{CO}+(2 n) \mathrm{H}_{2} \rightarrow \mathrm{C}_{n} \mathrm{H}_{2 n}+(n) \mathrm{H}_{2} \mathrm{O} \text { (eq.1) }
$$

Homogeneous transition metal complexes have been studied as models of the active sites of F-T catalysis. 5,6 While numerous systems have been developed, there is a growing focus on systems in which CO units are 
reductively combined to make oxygenated chains, $\left\{C_{n} \mathrm{O}_{n}\right\}^{\mathrm{m}-}(\mathrm{n}=2-6) .^{7-33}$ For example, Cloke and coworkers have shown that uranium(III) compounds can be used to construct carbon chains by combining two (ethynediolate), three (deltate) or four (squarate) CO units in a reductive coupling. ${ }^{34-36}$ Related reactions of low-oxidation state magnesium(I) complexes have been reported by Jones and coworkers. In the absence of a catalyst, three units of $\mathrm{CO}$ combine to form a cyclic deltate anion, ${ }^{37}$ while in the presence of $10 \mathrm{~mol} \%$ of $\left[\mathrm{Mo}(\mathrm{CO})_{6}\right]$ reductive hexamerisation to form a benzenehexolate derived from six units of $\mathrm{CO}$ occurred. ${ }^{38}$ Although the direct relevance of these systems to F-T catalysis remains a point of debate, their formation has captured the imagination of the community. Not least because these systems, and the mechanistic information captured from them, could act as a foundation for the development of homogeneous F-T catalysts for the selective construction of oxygenated hydrocarbons (e.g. polyols) from $\mathrm{CO}$ and $\mathrm{H}_{2} .{ }^{39}$

Despite these advances a clear limitation of the systems reported to date can be identified: in the majority of cases reactions result in the formation of isolable products in which $\left\{\mathrm{C}_{n} \mathrm{O}_{n}\right\}^{\mathrm{m}-}$ chains coordinate to metal complexes through thermodynamically stable $\mathrm{M}-\mathrm{O}$ bonds (e.g. $\mathrm{M}=\mathrm{U}, \mathrm{Mg}$ ). In contrast, cases in which reactive $\mathrm{M}-\mathrm{C}$ bonds are formed during carbon chain growth from $\mathrm{CO}$ are far rarer. ${ }^{6}$ Such systems may offer an opportunity to study the (often opaque) individual steps of carbon chain growth. In addition, although it is known that variation of the transition metal can influence product distributions in heterogeneous F-T catalysis ${ }^{40}$ there are few defined examples of organometallic reactions in which multiple carbon chain topologies are accessible from a single reaction.

Recently we reported the reactions of the aluminium(I) reagent $\left[\left\{(\operatorname{ArNCMe})_{2} \mathrm{CH}\right\} \mathrm{Al}\right](\mathrm{Ar}=2,6$-di-isopropylphenyl, [AI]) with $\left[\mathrm{W}(\mathrm{CO})_{6}\right] /$ CO mixtures. ${ }^{41}$ We documented a system in which $\left\{\mathrm{C}_{n} \mathrm{O}_{n}\right\}^{4-}(n=3,4)$ carbon chains could be synthesised through the cooperative action of the metal complexes. Remarkably these reactions not only proceeded from a defined transition metal carbonyl starting material, but they also led to the isolation of intermediates and products bearing reactive $\mathrm{Al}-\mathrm{C}$ bonds allowing us, for the first time, to elucidate the mechanism of chain growth from $C_{1} \rightarrow C_{3} \rightarrow C_{4}$ species. Herein, we show that the reaction scope can be expanded to a range of transition metal carbonyl precursors. We shed additional light on the mechanism of chain growth through isolation and characterisation of the $C_{2}$ intermediate and demonstrate that systematic variation of the transition metal impacts both the apparent rate and selectivity of the carboncarbon bond forming steps. 


\section{Results and Discussion}

$\mathrm{C}_{1}$ to $\mathrm{C}_{4}$ chain growth with $\mathrm{CO}$ : We have previously reported the reaction of $[\mathrm{Al}]$ with $\left[\mathrm{W}(\mathrm{CO})_{6}\right]$ and the isolation of the $C_{3}$ homologation product and its chain growth to a $C_{4}$ analogue. Keen to understand the role of the transition metal and expose the complete mechanism for chain growth from $\mathrm{C}_{1}$ to $\mathrm{C}_{4}$, we conducted a series of reactions in which the transition metal fragment was varied. Reaction of [Al] with a series of group 6-9 metal carbonyl complexes in the presence of CO was investigated (Scheme 1, Figure 1). The transition metal complexes were selected based on an 18-electron configuration and low-spin electronic structure. In addition, a cis-dicarbonyl motif was considered an essential reactive component for chain growth.

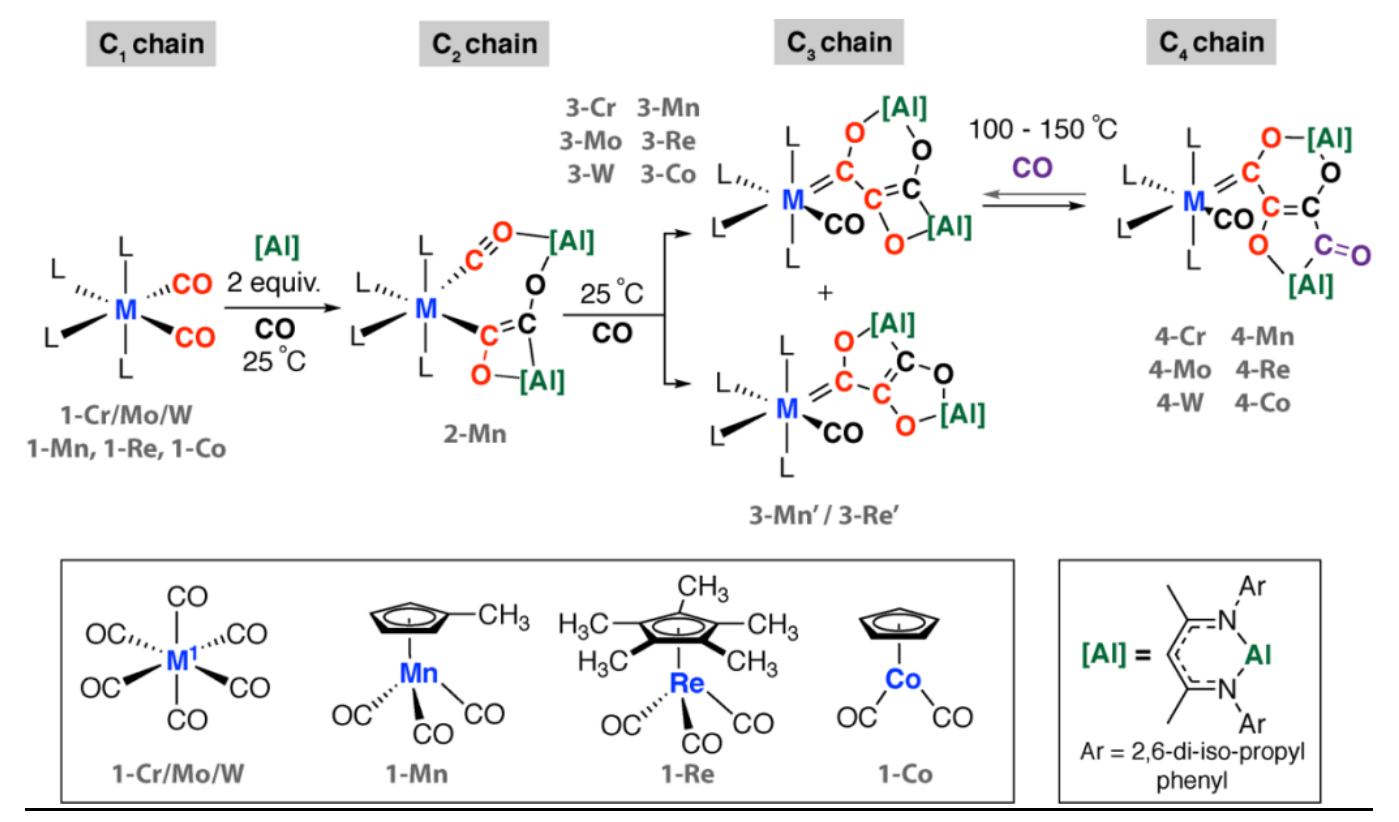

Scheme 1. Synthesis of $C_{2}$ to $C_{4}$ carbon chains by $C O$ homologation. Reactions conducted in $\mathrm{C}_{6} \mathrm{D}_{6}$ or $\mathrm{C}_{6} \mathrm{H}_{6}$.

These reactions allowed the isolation of a series of heterometallic products incorporating $C_{2}, C_{3}$ or $C_{4}$ carbon chains derived from a 2:1 stoichiometry of [AI] : 1-M. The aluminium(I) complex [AI] acts as a formal 2electron reductant in these reactions transferring a total of 4-electrons to the $\mathrm{CO}$ derived ligand in the chain growth process. Most notably modification of the electronics at the transition metal appears, qualitatively, to influence the reaction rate of each chain growth step, allowing isolation of a previously unobserved $C_{2}$ intermediate. Hence while reaction of $\mathbf{1 - C r}, \mathbf{1 - M o}, \mathbf{1 - W}$, or 1-Co with [AI] under CO (1 atm.) led directly to the $\mathrm{C}_{3}$ products $\mathbf{3}-\mathrm{Cr}, \mathbf{3 - M o}, \mathbf{3}-\mathbf{W}$, and $\mathbf{3}-\mathrm{Co}$ at $25^{\circ} \mathrm{C}$, in the case of 1-Mn conversion to the $\mathrm{C}_{2}$ homologue 2Mn was achieved. 
2-Mn is an incredibly rare example of a $\mathrm{C}_{2}$ homologation product that contains multiple reactive metalcarbon bonds. Although related complexes have been proposed as reaction intermediates, they are seldom isolated. 2-Mn could be isolated and shown to convert to 3-Mn under an atmosphere of $\mathrm{CO}$ at $25^{\circ} \mathrm{C}$. A minor isomeric product tentatively assigned as $\mathbf{3}-\mathbf{M n}$ ' was observed alongside $\mathbf{3}-\mathbf{M n}$ in crude reactions mixtures. 3$\mathbf{M n}$ and 3-Mn' form in a 9:1 ratio and likely co-crystallise: 3-Mn could not be separated from 3-Mn' by fractional crystallisation. Analogous reactions with the rhenium precursor ultimately shed light on this data. The reaction of 1-Re with CO formed a 3:1 mixture of two products from CO homologation, the expected product 3-Re which contained [6,4]-fused ring system, alongside 3-Re' - an isomer with a [5,5]-fused ring system (Scheme 1)..$^{42}$ The ratio of 3-Re : 3-Re' was unaffected by heating for $18 \mathrm{~h}$ at $100{ }^{\circ} \mathrm{C}$. Furthermore, isolated samples of 3-Re do not convert to mixtures of 3-Re and 3-Re'. DFT calculations suggest that 3-Re' is more stable than $\mathbf{3}-\mathbf{R e}$ by $18.8 \mathrm{kcal} \mathrm{mol}^{-1}$, despite forming as the minor product. These data suggest the reactions are under kinetic control with the selectivity determining step occurring during the mechanism of $C_{1}$ to $C_{3}$ chain growth. In all other cases, $[6,4]$-fused ring systems were identified as the only isomer of the $C_{3}$ chain. This observation along with the variation of product ratios with different transition metal precursors, i.e. 3-Mn : 3-Mn' (9:1) and 3-Re : 3-Re' (3:1), demonstrate that the transition metal fragment impacts the selectivity of the $\mathrm{CO}$ homologation process.

Under more forcing conditions ( $1 \mathrm{~atm} ., 100^{\circ} \mathrm{C}$ ), 3-Cr, 3-Mo, 3-W, 3-Mn, and 3-Co could all be converted to the $\mathrm{C}_{4}$ products 4-Cr, 4-Mo, 4-W, 4-Mn, and 4-Co respectively. These reactions were found to be reversible and at elevated temperatures $\left(100-150^{\circ} \mathrm{C}\right)$ under a dinitrogen atmosphere the de-insertion of $\mathrm{CO}$ could be observed spectroscopically. Mixtures of 3-Re : $\mathbf{3}-\mathbf{R} \mathbf{e}^{\prime}$ reacted selectively to form 4-Re. Only 3-Re was consumed in this reaction suggesting that the strained $[6,4]$ fused ring system is more labile than the $[5,5]$ isomer. 4-Re could be separated from 3-Re' through fractional crystallisation. Subsequent heating of 4-Re under static vacuum to effect $\mathrm{CO}$ de-insertion allowed the isolation of pure samples of 3-Re.

Multinuclear NMR and Infrared Characterisation of 2-4: In $\mathrm{C}_{6} \mathrm{D}_{6}$ solution, 2-Mn displays ${ }^{13} \mathrm{C}$ NMR resonances for the carbonyl and isocarbonyl ligands at $\delta=236.8$ and $189.5 \mathrm{ppm}$ respectively, along with diagnostic resonances for the $C_{2}$ ligand fragment at $\delta=249.2$ and $167.2 \mathrm{ppm}$. The most deshielded resonance is assigned to the $\mathrm{C}^{2}$ position and is consistent with the location of this atomic site adjacent to the transition metal. In the solid-state, the IR spectrum of 2-Mn shows an absorption at $1921 \mathrm{~cm}^{-1}$ assigned to the $v(\mathrm{CO})$ vibrations of the carbonyl ligand. The vibration(s) associated with the isocarbonyl ligand could not be assigned clearly as they overlap with stretches associated with the ligand and are shifted into the fingerprint region. The $C_{3}$ homologation products, 3-Cr, 3-W, 3-Mn, 3-Re and 3-Co are characterised by diagnostic ${ }^{13} \mathrm{C}$ resonances ranging from $\delta=265-315 \mathrm{ppm}$ and $167-172 \mathrm{ppm}$ for the $C^{1}$ and $C^{2}$ positions respectively. The largest variation in these data across the series is seen for the $\mathrm{C}^{1}$ position as it is connected directly to the transition metal and influenced by the nature of $\mathrm{M}=\mathrm{C}^{1}$ bond. These chemical shifts are consistent with the assignment 
as a metallocarbene ligand. ${ }^{43-45}$ Chemical shifts of the $C^{2}$ position are insulated from the transition metal fragment and vary little across the series. In nearly all cases the quadrupolar broadening associated with the ${ }^{27} \mathrm{Al}$ nucleus prevents identification of the $\mathrm{C}^{3}$ resonance. Despite the different topologies, chemical shifts of the $C^{1}$ and $C^{2}$ position of 3-Re and 3-Re' are remarkably similar. Characterisation of ${ }^{13} C$ enriched isotopomers of 3-W allow aspects of the $J$ coupling in the carbon chain to be resolved and the $C^{3}$ resonance to be unambiguously identified. Hence, ${ }^{13} \mathrm{CO}$ enriched $\mathbf{3}-\mathbf{W}$ shows the $\mathrm{C}^{3}$ resonance at $\delta=176.5 \mathrm{ppm}$. The coupling constants in the chain were determined as ${ }^{1} J_{\mathrm{C} 2-\mathrm{C} 3}=41.8 \mathrm{~Hz},{ }^{1} J_{\mathrm{C} 1-\mathrm{C} 2}=37.1 \mathrm{~Hz}$, along with ${ }^{1} \mathrm{~J}_{\mathrm{W}-\mathrm{C} 1}=102 \mathrm{~Hz}$ determined from natural abundance satellites of ${ }^{183} \mathrm{~W}$.

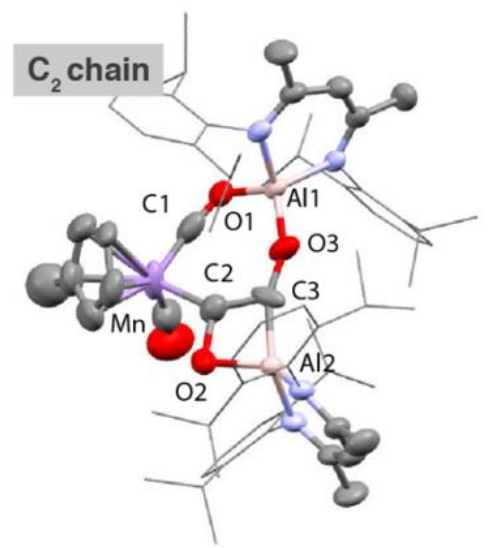

2-Mn

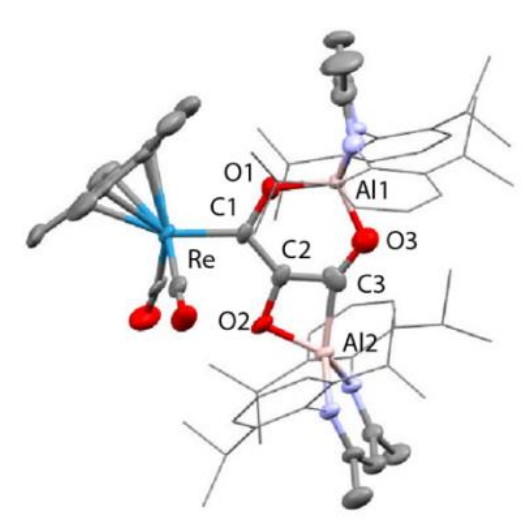

3-Re

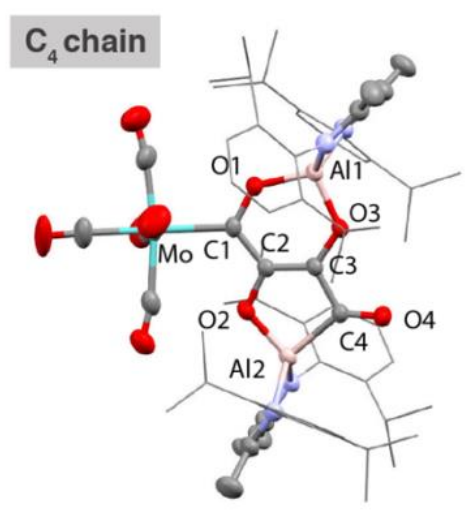

4-Mo

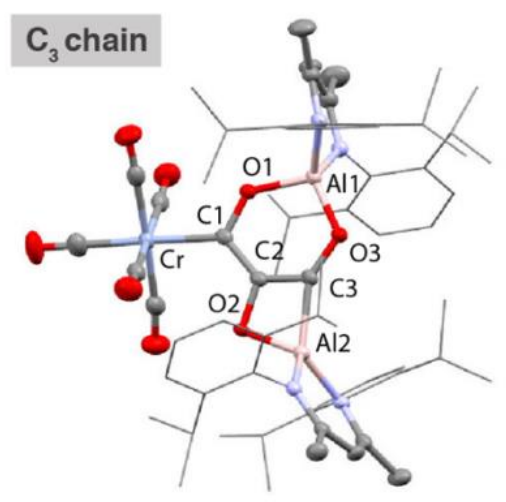

$3-\mathrm{Cr}$

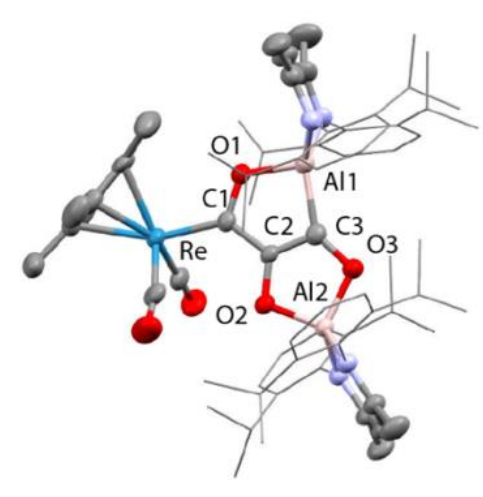

3- $\mathbf{R e}^{\prime}$

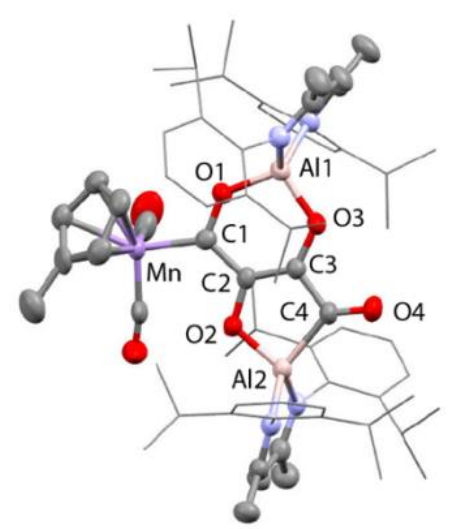

4-Mn

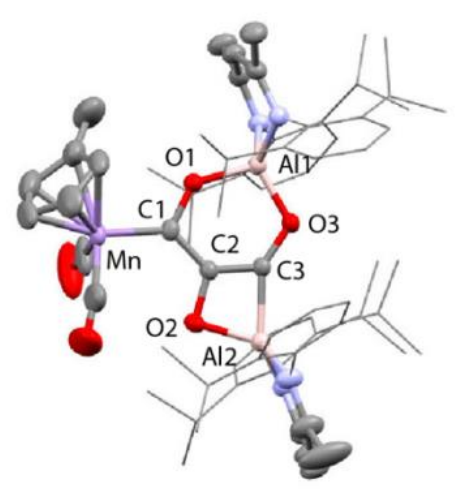

3-Mn

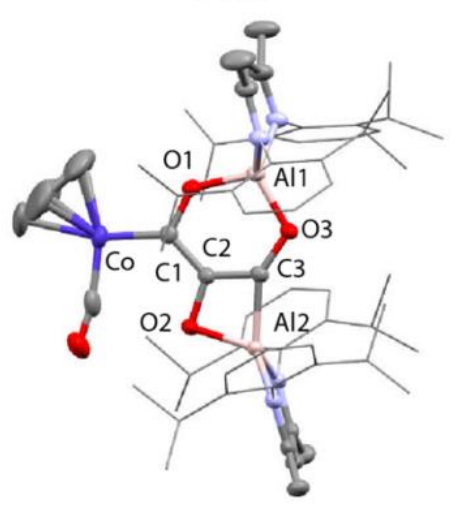

3-Co

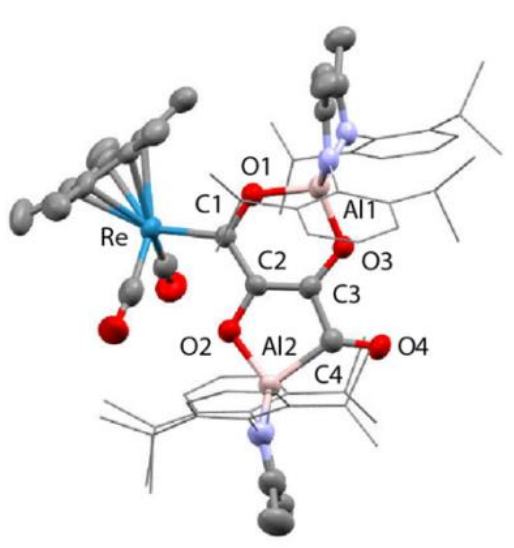

4-Re

Figure 1. Solid State structures of 2-Mn, 3-Cr, 3-Mn, 3-Re, 3-Re', 3-Co, 4-Mo, 4-Mn and 4-Re. 
The $\mathrm{C}_{4}$ homologation products, $\mathbf{4 - W}, \mathbf{4 - M n}$ and $\mathbf{4 - R e}$ are characterised by diagnostic ${ }^{13} \mathrm{C}$ resonances for the $C^{1}, C^{2}$, and $C^{3}$ positions which range from $\delta=281-349 \mathrm{ppm}, 161-169 \mathrm{ppm}$, and $135-145 \mathrm{ppm}$ respectively. ${ }^{13} \mathrm{C}$ enriched samples of $\mathbf{4}-\mathbf{W}$ provide ${ }^{13} \mathrm{C}-{ }^{13} \mathrm{C}$ coupling constants of the carbon chain with ${ }^{1} \mathrm{~J}_{\mathrm{C} 1-\mathrm{C} 2}=35.8 \mathrm{~Hz},{ }^{1} \mathrm{~J}_{\mathrm{C}-}$ $\mathrm{C}_{4}=27.4 \mathrm{~Hz}$, and ${ }^{2} J_{\mathrm{C} 2-\mathrm{C} 4}=9.1 \mathrm{~Hz}$. The coupling from $\mathrm{W}$ to the $\mathrm{C}^{1}$ position of $4-\mathbf{W}$ is ${ }^{1} \mathrm{~J}_{\mathrm{W}-\mathrm{C} 1}=109 \mathrm{~Hz}$ and is similar to the value observed in $\mathbf{3}-\mathbf{W}$, suggesting little change in the nature of the carbene ligand on elongation of the carbon chain from $\mathrm{C}_{3}$ to $\mathrm{C}_{4 .}{ }^{41}$

Solid-State Characterisation of 2-4: The X-ray structure of 2-Mn incorporates a [7,4] ortho-fused ring system. Bond lengths and angles at the main group fragments support the assignment of an aluminium +3 oxidation state. ${ }^{46}$ The 7-membered ring system includes both $\mathrm{Mn}$ and $\mathrm{Al}$ centres along with the $\mathrm{C}_{2}$ fragment and isocarbonyl ligand. The $C^{1}---C^{2}$ distance is $\sim 2.6 \AA$ and the system is pre-organised for carbon-carbon bond formation through ring contraction. The $\mathrm{C}^{1}-\mathrm{O}^{1}$ bond length of $1.209(6) \AA$ of the isocarbonyl ligand is $\sim 0.1 \AA$ longer than the terminal carbonyl of 1.097(8) $\AA$. The $\mathrm{C}_{2}$ fragment is bound to $\mathrm{Mn}$ through a short $\mathrm{Mn}-\mathrm{C}^{2}$ bond of 1.971(5) $\AA$. The $C^{2}-C^{3}$ distance of $1.481(7) \AA$ is beyond that expected for a $C=C$ bond. Similarly, the $C^{2}-O^{2}$ bond of 1.500(6) $\AA$ is long. Both these bond lengths shorten upon forming the ring contraction product 3$\mathbf{M n}$. While the $\mathrm{C}^{3}-\mathrm{O}^{3}$ bond length remains near constant in 2-Mn and 3-Mn taking values of 1.365(5) and 1.364(4) $\AA$, the $\mathrm{Al}-\mathrm{C}^{3}$ length is $\sim 0.1$ A shorter in 2-Mn than 3-Mn and the $\mathrm{O}^{2}-\mathrm{Al}-\mathrm{C}^{2}$ angle is more obtuse. Both the lengthening of the $\mathrm{C} \equiv \mathrm{O}$ bond and the unusual bonding features of the $\mathrm{C}_{2}$ fragment are consistent with electron transfer from Al to $\mathrm{CO}$ on reaction of 1-Mn. For comparison, $\left\{\mathrm{C}_{2} \mathrm{O}_{2}\right\}^{2-}$ 'zig-zag' intermediates have been proposed in the formation $\left\{\mathrm{C}_{2} \mathrm{O}_{2}\right\}^{2-}$ ethynediolate and $\left\{\mathrm{C}_{3} \mathrm{O}_{3}\right\}^{2-}$ deltate complexes from reaction of $\mathrm{CO}$ with uranium(III) and magnesium(I) compounds. ${ }^{47}$ While neither isolated nor spectroscopically characterised, these species have been inferred by DFT studies. The $C_{2}$ fragment of 2-Mn related to these proposed zig-zag intermediates, however the $\mathrm{C}_{2}$ ligand in $\mathbf{2}-\mathbf{M n}$ shows considerable asymmetry and a unique elongated $\mathrm{C}-\mathrm{O}$ bond that strongly suggests an unusual electronic structure (Figure 2).
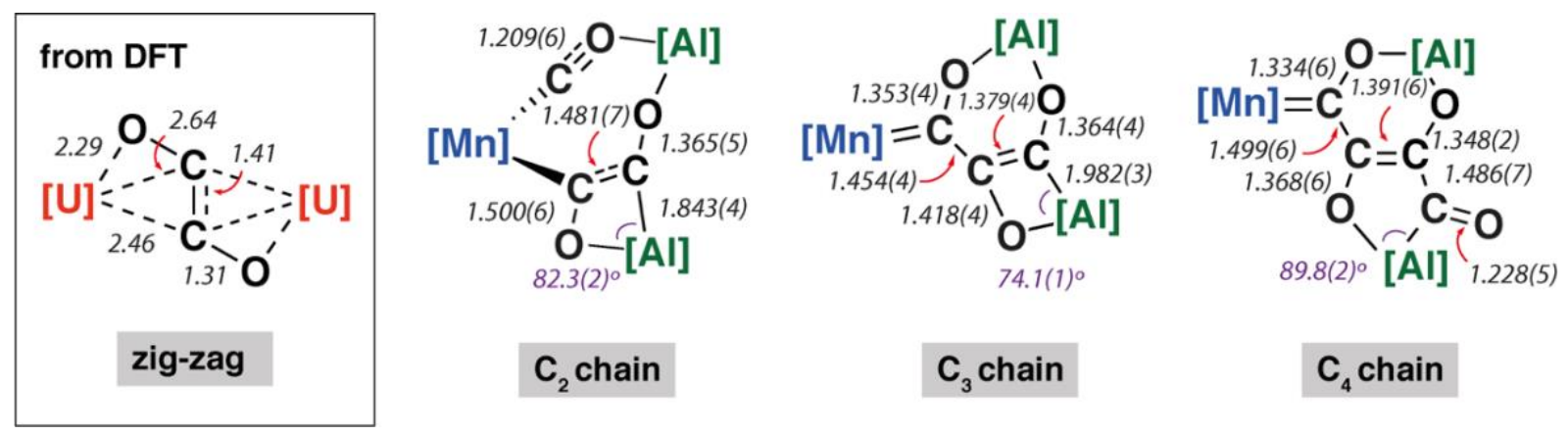

Figure 2. Comparison of key bond lengths and angles $\left(\AA\right.$ or $\left.^{\circ}\right)$ in 2-Mn, 3-Mn and 4-Mn alongside a calculated zig-zag intermediate. 


\begin{tabular}{cc|ccccccc|}
\hline & 2-Mn & 3-Cr & 3-Mo[a] & 3-W & 3-Mn & 3-Re & 3-Re' & 3-Co \\
\hline M-C1 & $1.742(6)$ & $2.055(3)$ & $2.250(4)$ & $2.195(3)$ & $1.922(3)$ & $2.019(6)$ & $2.015(4)$ & $1.810(2)$ \\
M-C2 & $1.971(5)$ & - & - & - & - & - & - & - \\
C1--C2 & $2.633(7)$ & $1.445(4)$ & $1.428(6)$ & $1.437(4)$ & $1.454(5)$ & $1.482(9)$ & $1.485(6)$ & $1.447(3)$ \\
C2-C3 & $1.481(7)$ & $1.375(4)$ & $1.399(6)$ & $1.379(4)$ & $1.386(5)$ & $1.382(10)$ & $1.372(7)$ & $1.380(3)$ \\
C1-O1 & $1.209(6)$ & $1.335(3)$ & $1.337(5)$ & $1.337(3)$ & $1.353(4)$ & $1.366(8)$ & $1.344(6)$ & $1.353(3)$ \\
C2-O2 & $1.500(6)$ & $1.412(3)$ & $1.403(5)$ & $1.409(3)$ & $1.418(4)$ & $1.410(9)$ & $1.375(5)$ & $1.409(3)$ \\
C3-O3 & $1.365(5)$ & $1.362(3)$ & $1.328(5)$ & $1.360(3)$ & $1.364(4)$ & $1.321(9)$ & $1.383(6)$ & $1.371(3)$ \\
Al-C & $1.843(4)$ & $1.979(3)$ & $1.977(4)$ & $1.982(3)$ & $1.942(3)$ & $1.993(8)$ & $1.953(5)$ & $1.946(2)$ \\
O-Al2-C & $82.25(19)$ & $73.89(10)$ & $74.82(16)$ & $74.13(11)$ & $75.37(13)$ & $73.4(3)$ & $90.02(19)$ & $75.50(9)$ \\
\hline
\end{tabular}

Table 1. Selected Bond lengths $(\AA)$ and angles $\left({ }^{\circ}\right)$ from solid state data of compounds 2 and 3. [a] as two molecules were found in the asymmetric unit, data is provided for 3-Mo(B) one of these molecules. [b]

Data from reference 41.

\begin{tabular}{cccccc}
\hline & 4-Cr & 4-Mo & 4-W[a] & 4-Mn & 4-Re \\
\hline M-C1 & $2.084(4)$ & $2.231(2)$ & $2.233(4)$ & $1.902(4)$ & $2.030(4)$ \\
C1-C2 & $1.474(5)$ & $1.466(4)$ & $1.457(5)$ & $1.499(6)$ & $1.497(6)$ \\
C2-C3 & $1.374(5)$ & $1.396(3)$ & $1.396(5)$ & $1.391(6)$ & $1.407(7)$ \\
C3-C4 & $1.510(5)$ & $1.499(4)$ & $1.507(5)$ & $1.486(7)$ & $1.494(7)$ \\
C1-O1 & $1.322(4)$ & $1.322(3)$ & $1.322(5)$ & $1.334(6)$ & $1.330(6)$ \\
C2-O2 & $1.370(4)$ & $1.375(3)$ & $1.373(5)$ & $1.368(6)$ & $1.372(6)$ \\
C3-O3 & $1.335(4)$ & $1.337(3)$ & $1.334(5)$ & $1.348(6)$ & $1.353(6)$ \\
C4-O4 & $1.246(5)$ & $1.229(3)$ & $1.233(5)$ & $1.228(5)$ & $1.246(6)$ \\
Al-C & $1.990(4)$ & $2.002(3)$ & $1.996(4)$ & $2.010(5)$ & $1.990(5)$ \\
O-Al2-C & $90.19(14)$ & $90.83(10)$ & $90.37(15)$ & $89.81(17)$ & $91.16(18)$
\end{tabular}

Table 2. Selected Bond lengths $(\AA)$ and angles $\left({ }^{\circ}\right)$ from solid state data of compounds 4. [a] Data from reference 41.

Except for the transition metal fragment, the solid-state structures of $\mathbf{3}$ and $\mathbf{4}$ vary only slightly within their series. Key bonding metrics for both the $C_{3}$ and $C_{4}$ carbon chains are consistent, within error, across every single crystal X-ray diffraction study reported herein. Although we have commented on these types of structures before, some details are included here for clarity. 3 possesses an ortho-fused $[6,4]$ ring system derived from contraction of the $[7,4]$ system in $\mathbf{2}$, while $\mathbf{4}$ contains a $[6,5]$ ring system. The side product 3-Re' contains a $[5,5]$ ortho-fused ring system. In all cases, the carbon atoms of both the $C_{3}$ and $C_{4}$ carbon chains are close to idealised $s p^{2}$ hybridised. The $C^{1}-C^{2}$ and $C^{2}-C^{3}$ bond lengths of 3 range from $1.428(6)-1.482(9)$ and 1.375(4) - 1.399(6) A respectively; those for $\mathbf{4}$ are similar. In combination with the $C^{3}-C^{4}$ lengths of 4 which vary from $1.486(7)-1.510(5) \AA$, the data are consistent with an alternating array of $C-C$ and $C=C$ bonds in the carbon chains. The $\mathrm{C}^{1}-\mathrm{O}^{1}, \mathrm{C}^{2}-\mathrm{O}^{2}$ and $\mathrm{C}^{3}-\mathrm{O}^{3}$ bond lengths of $\mathbf{3}$ and $\mathbf{4}$ range from approximately 1.3 to $1.4 \AA$ and are consistent their assignment as $\mathrm{C}-\mathrm{O}$ bonds, while the $\mathrm{C}^{4}-\mathrm{O}^{4}$ distances of 4 are shorter at $1.228(5)$ -1.246(6) $\AA$ and assigned as C=O bonds. The bond lengths in 3-Re and 3-Re' are remarkably similar, despite the isomerisation of the $[6,4]$ to $[5,5]$ ring system, the major difference is expansion of the O-Al-C angle of 
the smaller (4- or 5-membered ring) from $73.4(3)$ to $90.0(2)^{\circ}$. It should be noted, that despite these metrics, the localised resonance structures are an imperfect description as there is the potential for delocalisation of electrons within the $\left\{\mathrm{C}_{3} \mathrm{O}_{3}\right\}^{4-}$ and $\left\{\mathrm{C}_{4} \mathrm{O}_{4}\right\}^{4-}$ units (vide infra). Of the data considered only the $\mathrm{M}=\mathrm{C}^{1}$ distance shows any real variation across the series. Nevertheless, comparison of 3-W with 4-W, 3-Re with 4-Re, and 3-Mn with 4-Mn shows that there is no change in this bond length, within error, on elongation of the carbon chain from $\mathrm{C}_{3}$ to $\mathrm{C}_{4}$. This observation is consistent with NMR data and the insensitivity of the $1 / J_{W-C 1}$ coupling constants to chain length. Moreover, when considering 3-Cr, 3-W, 3-Mo, 3-Mn, 3-Re, and 3-Co if the covalent radii of the transition metal are factored in, the normalised $\mathrm{M}=\mathrm{C}^{1}$ bond lengths are remarkably similar with a slight contraction occurring across the period (group $9<$ group $7<$ group 6 ).$^{48}$

Electronic Structure of 2-4: Members of the manganese series (2-Mn, 3-Mn, and 4-Mn) were interrogated by DFT calculations. Geometries were optimised in the gas-phase using the $\omega B 97 x$ functional with a split 6 $31 \mathrm{G}^{* *}(\mathrm{C}, \mathrm{H}, \mathrm{N}, \mathrm{O}) /$ SDDAll $(\mathrm{Al}, \mathrm{Mn})$ basis set. These calculations provide insight into the electronic structure of the carbon-chain, how this responds to the number of carbon atoms, and how the carbon chain interacts with the transition metal and main group centres.

NBO calculations (version 6.0) show that the primary interaction between the carbon chains and aluminium atoms is ionic. The NPA charges across all Al sites in $\mathbf{2}-\mathbf{M n}, \mathbf{3}-\mathbf{M n}$, and 4-Mn range from +2.02 to +2.25 . The ionic component to the bonding is further reflected in the large charge localisation on oxygen ( -0.86 to $1.05)$ and carbon $(-0.48$ to -0.04$)$ atoms directly connected to $\mathrm{Al}$ in these complexes. These data are consistent with assignment of a formal +3 oxidation state to aluminium and consideration of the chain as a $\left\{\mathrm{C}_{\mathrm{n}} \mathrm{O}_{\mathrm{n}}\right\}^{4-}(\mathrm{n}=2-4)$ fragment. For 3-Mn and 4-Mn, the Wiberg Bond Indices (WBI) between the C-C ( $\mathrm{C}^{1}-\mathrm{C}^{2}=$ $\left.1.07,1.09 ; C^{2}-C^{3}=1.55,1.57 ; C^{3}-C^{4}=1.03\right)$ and $C-O\left(C^{1}-O^{1}=1.14,1.18 ; C^{2}-O^{2}=0.96,1.02 ; C^{3}-O^{3}=1.03\right.$, 1.04; $\mathrm{C}^{4}-\mathrm{O}^{4}=1.76$ ) atoms of the $\left\{\mathrm{C}_{n} \mathrm{O}_{n}\right\}^{4-}$ chain reflect the alternating array of single and double bonds suggested by the solid-state structures. While these data hint at a degree of delocalisation of electron density across the 4-, 5- and 6-membered rings of 3-Mn and 4-Mn, NICS(0) calculations show that these ring systems are essentially non-aromatic (see supporting information).

The relatively large WBI for the $\mathrm{C}^{1}-\mathrm{C}^{2}$ and $\mathrm{C}^{1}-\mathrm{O}^{1}$ units of 3-Mn and 4-Mn warrants further comment but requires consideration of the nature of $\mathrm{M}=\mathrm{C}^{1}$ bond to explain. The manganese centre of these complexes bears a slight negative charge $(-0.34)$ while the adjacent carbon atom $C^{1}$ is electropositive $(+0.40,+0.42)$. The calculated WBI for the bond between $\mathrm{Mn}$ and $\mathrm{C}^{1}(0.83)$ is smaller than that to the carbon atom of the terminal carbonyl ligand (0.95-0.99). The data vary little between 3-Mn and 4-Mn and along with the nominal changes in $\mathrm{M}=\mathrm{C}^{1}$ bond length and ${ }^{1} \mathrm{~J}_{\mathrm{W}-\mathrm{c}}$ coupling constant strongly suggest that the metal-ligand interaction in these complexes is very similar. ETS-NOCV calculations are consistent with the formalisation of the $M=C^{1}$ interaction of 3-Mn as a metallocarbene. The total $\Delta \mathrm{E}_{\text {orb }}$ of the carbon chain ligand and transition metal 
fragment of 3-Mn is $-80.1 \mathrm{kcal} \mathrm{mol}^{-1}$. There are two principal components $\Delta \rho_{1}\left(-41.7 \mathrm{kcal} \mathrm{mol}^{-1}\right)$ and $\Delta \rho_{2}(-$ $25.2 \mathrm{kcal} \mathrm{mol}^{-1}$ ) comprised of $\sigma$-donation from a filled $\mathrm{C}^{1}$-based orbital to the metal, along with $\pi$ backdonation from a metal $d$-orbital to a $p_{z}$-based orbital on $C^{1}$ (Figure 3a). A similar bonding situation is found in 4-Mn. Charge localisation on $\mathrm{Mn}$, along with the large $\mathrm{C}^{1-} \mathrm{O}^{1}$ and $\mathrm{C}^{1}-\mathrm{C}^{2}$ WBIs can be rationalised by a series of zwitterionic resonance structures, reminiscent of those commonly invoked for Fischer carbenes (Figure 3b).
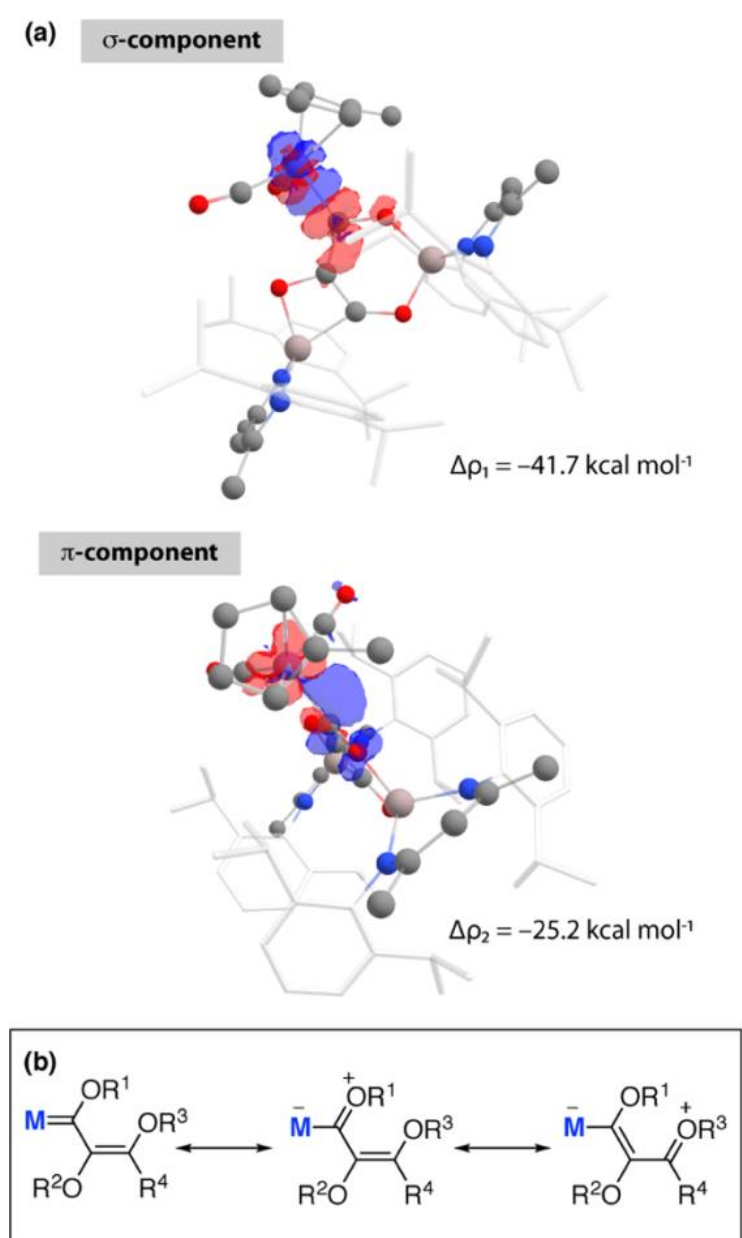

Figure 3. (a) ETS-NOCV calculations on 3-Mn showing principal components $\Delta \rho_{1}$ and $\Delta \rho_{1}$ of $\Delta E_{\text {orb }}$. Charge flow from red to blue. (b) Simplified resonances structures for neutral and zwitterionic bonding components of 3 .

The electronic structure of 2-Mn is more complex. While variable temperature NMR data suggests that 2-Mn may undergo fluxional rearrangement in solution (vide infra), there is no evidence this species is paramagnetic. The calculated singlet-triplet gap for $\mathbf{2 - M n}$ is $38.0 \mathrm{kcal} \mathrm{mol}^{-1}$, while such values are known to be functional dependent, the data strongly suggesting a singlet ground state. The $\mathrm{Mn}-\mathrm{C}^{2} \mathrm{WBI}$ in 2-Mn (0.58) is notably lower than the $\mathrm{Mn}-\mathrm{C}^{1}$ values in 3-Mn and 4-Mn. In combination with the large $\mathrm{C}^{2}-\mathrm{C}^{3} \mathrm{WBI}$ (1.79) and increased charge accumulation on $\mathrm{C}^{2}(+0.15), \mathrm{C}^{3}(-0.48), \mathrm{Mn}(-0.32)$ in this complex relative to 3-Mn and 4-Mn, these calculations suggest a unique electronic structure of 2-Mn with the $C_{2}$ ligand adopting some vinyl character. ETS-NOCV calculations support this assertion and capture only a $\sigma$-component to the bonding 
with no clear $\pi$-backdonation from the metal to $C^{2}$ (supporting information). The WBIs calculated for the isocarbonyl fragment suggest a lengthened $C=O$ bond (1.38) and compressed $M=C$ bond (1.52) relative to the terminal CO ligand as is typical of bridging isocarbonyl fragments.

Mechanism of $C_{1}$ to $C_{4}$ Chain Growth: Preliminary experiments using ${ }^{13} \mathrm{C}$ labelled materials $\left[\mathrm{W}\left({ }^{13} \mathrm{CO}\right)_{6}\right]$ and ${ }^{13} \mathrm{CO}$ showed that the first two carbon atoms of 3-W and $\mathbf{4}-\mathbf{W}\left(\mathrm{C}^{1}\right.$ and $\left.\mathrm{C}^{2}\right)$ derive from the transition metal carbonyl, while the second two carbon atoms $\left(\mathrm{C}^{3}\right.$ and $\left.\mathrm{C}^{4}\right)$ derive from atmospheric $\mathrm{CO}$. Further, these labelling experiments reveal that an additional equivalent of atmospheric $\mathrm{CO}$ is incorporated into the cis-position of the transition metal complex during the reaction sequence. Any plausible mechanism for chain formation must account for these isotopic labelling experiments.

The DFT calculations were expanded to consider the formation of the key intermediate 2-Mn along with the interconversion of 2-Mn $\rightarrow$ 3-Mn $\rightarrow$ 4-Mn (Figure 4). The $C_{1}$ to $C_{4}$ chain-growth mechanism involves alternating reduction and oxidation events at the growing carbon, by [AI] and CO respectively. Stationary point geometry optimisation and frequency analysis were performed using the $\omega B 97 x$ functional. ${ }^{49}$ Single point energies were calculated using the $M 06 L^{50}$ functional with dispersion $(D 3)^{51}$ and solvent (PCM, benzene $)^{52}$ corrections. The M06L functional has been previously benchmarked to provide good agreement with experimentally derived thermodynamic parameters on closely related systems. ${ }^{53}$

The calculated pathway begins with nucleophilic attack of $[\mathrm{Al}]$ onto a $\mathrm{C}^{2} \equiv \mathrm{O}^{2}$ unit bound to the transitionmetal centre, forming Int-1. ${ }^{54,55} \mathrm{~A}$ single transition state connects the starting materials, 1-Mn and [Al], with Int-1. The aluminium centre is bound to both the $\mathrm{C}^{2}$ and $\mathrm{O}^{2}$ atoms in Int-1 to form a three-membered ring. Hence, this step could more precisely be described as a $(2+1)$ cycloaddition from the perspective of [AI]. NBO analysis of Int-1 shows that $2 \mathrm{e}^{-}$have been transferred from [AI] to the $\mathrm{CO}$ unit; both the natural charges on $\mathrm{C}^{2}(-0.11)$ and $\mathrm{O}^{2}(-0.85)$ are lower than that of free $\mathrm{CO}(+0.69$ and -0.52 respectively). Donation of the lonepair of [AI] into the $\mathrm{CO} \pi^{*}$ orbital is a key interaction in TS-1.

Subsequent insertion of exogeneous $\mathrm{CO}$ into the Al-C bond of Int-1 is calculated to be facile. This occurs via a single transition state, TS-2, to form the acyl intermediate Int-2. This step of the mechanism is the first carbon-carbon bond forming event, but it constructs the $C^{2}-C^{3}$ bond of the chain. The NPA charge analysis shows that insertion of $\mathrm{C}^{3} \equiv \mathrm{O}^{3}$ into the $\mathrm{Al}-\mathrm{C}^{2}$ bond of Int-1 is accompanied by partial oxidation of the carbon chain; both carbon atoms of Int-2 have positive NPA charges $\left(C^{2}+0.31 ; C^{3}+0.02\right)$. There is literature precedent for the insertion of $\mathrm{CO}$ into three-membered aluminocyclopropanes ${ }^{56}$ and aluminocyclopropenes. ${ }^{57}$ Prior calculations from our group have shown that these reactions are reminiscent of migratory insertion of $\mathrm{CO}$ at transition metal centres but have a propensity to occur in a concerted manner. ${ }^{57}$ The reaction of a second equivalent of [Al] with Int-2 is calculated to be thermodynamically downhill $\left(\Delta \mathrm{G}^{\circ}{ }_{298 \mathrm{~K}}=-48.2 \mathrm{kcal} \mathrm{mol}{ }^{-1}\right)$. The 
NPA charge of the $C^{2}$ and $C^{3}$ carbon in $2-\mathbf{M n}(+0.15,-0.48)$ are lower than those in Int-2 $(+0.31,+0.02)$ reflecting the reduction of the carbon chain in this step. Although a transition state could not be located for this intermolecular process, the step is entirely feasible and leads directly to the key intermediate 2-Mn, which has been isolated and crystallographically characterised.

The structure of 2-Mn is preorganised for the migratory insertion of the $\mathrm{C}^{1} \equiv \mathrm{O}^{1}$ isocarbonyl ligand into the $\mathrm{Mn}-\mathrm{C}^{2}$ bond. The $\mathrm{C}^{1}-\mathrm{C}^{2}$ bond along with the $[6,4]$ fused ring system of 3-Mn is formed in this reaction step. A single transition state, TS-3, connects $\mathbf{2}-\mathbf{M n}$ with Int-3. The reaction barrier from $\mathbf{2}-\mathbf{M n}$ to TS-3 $\left(\Delta \mathrm{G}^{\ddagger}{ }_{298 \mathrm{~K}}=\right.$ $26.0 \mathrm{kcal} \mathrm{mol}^{-1,}$ ) is consistent with this being a slow step, and combined with the relative thermodynamic stability of 2-Mn, predicts this intermediate to be an isolable species. For comparison, the equivalent step in the pathway from 1-W is calculated to occur via a lower in energy transition state (see supporting Information) and all attempts to detect 2-W, the analogue of 2-Mn, failed. Migratory insertion reactions at transition metal centres are commonly reversible, with trapping of the products by an exogeneous ligand providing a thermodynamic driving force for the forward reaction..$^{58}$ In line with this statement, the formation of Int-3 from 2-Mn is calculated to be mildly endergonic $\left(\Delta \mathrm{G}^{\circ}{ }_{298 \mathrm{~K}}=+3.7 \mathrm{kcal} \mathrm{mol}^{-1}\right)$ and likely reversible. Coordination of $\mathrm{CO}$ to Int-3 results in the formation of 3-Mn and is downhill from $\mathbf{2}-\mathbf{M n}\left(\Delta \mathrm{G}^{\circ}{ }_{298 \mathrm{k}}=-41.1 \mathrm{kcal}\right.$ $\left.\mathrm{mol}^{-1}\right)$. This coordination event explains the incorporation of exogenous $\mathrm{CO}$ into the cis-position of the transition metal fragment observed in isotopic labelling studies.

Insertion of a further equivalent of exogeneous $\mathrm{C}^{4} \equiv \mathrm{O}^{4}$ into the $\mathrm{Mn}-\mathrm{C}^{3}$ bond of $\mathbf{3}-\mathrm{Mn}$ is calculated to occur by TS-4 and results in the construction of the $\mathrm{C}^{3}-\mathrm{C}^{4}$ bond and formation of 4-Mn. The activation barrier and thermodynamics for this step $\left(\Delta \mathrm{G}^{\ddagger}{ }_{298 \mathrm{~K}}=21.2 \mathrm{kcal} \mathrm{mol}^{-1} ; \Delta \mathrm{G}^{\circ}{ }_{298 \mathrm{~K}}=-13.5 \mathrm{kcal} \mathrm{mol}^{-1}\right)$ again suggest that 3-Mn should be isolable. The calculations are also consistent with the reverse reaction, deinsertion of $C^{4} \equiv \mathrm{O}^{4}$ from 4-Mn to form 3-Mn, being feasible under forcing conditions $\left(\Delta G_{298 \mathrm{~K}}^{\ddagger}=34.7 \mathrm{kcal} \mathrm{mol}^{-1}\right)$ as observed experimentally. ${ }^{59}$

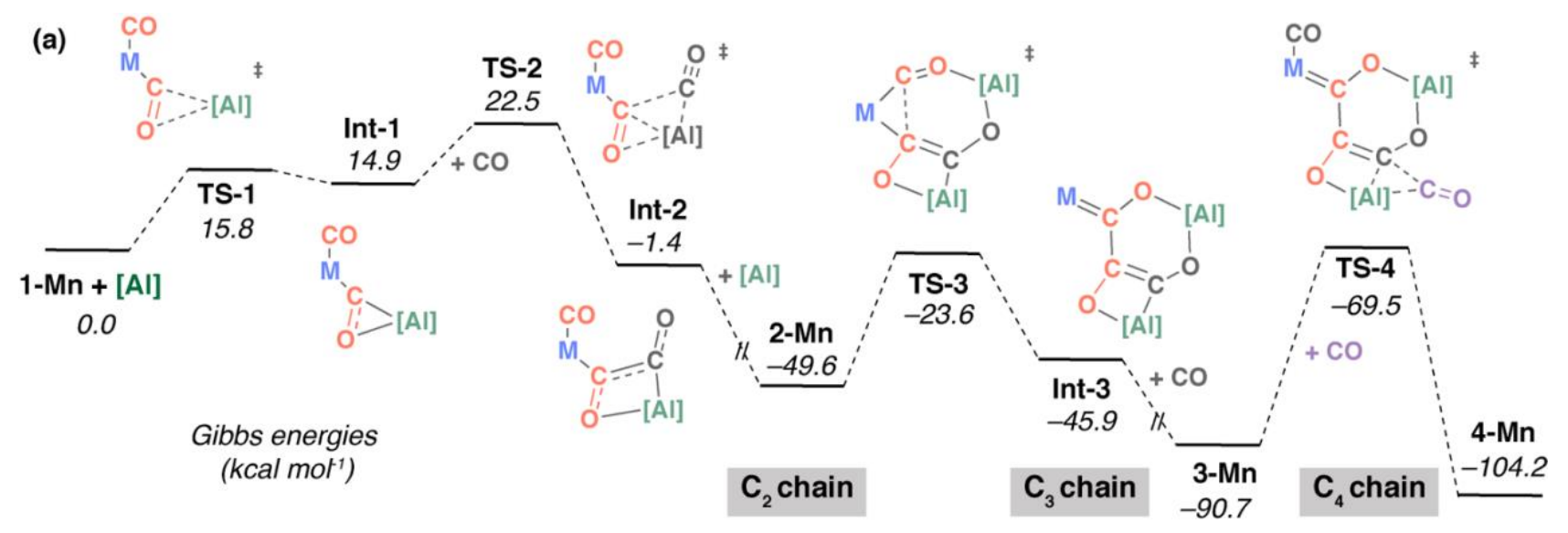

Figure 4. DFT calculated mechanism for $\mathrm{C}_{1}$ to $\mathrm{C}_{4}$ from 1-Mn, [AI] and $\mathrm{CO}$ via isolated intermediates 2-Mn, 3$\mathrm{Mn}$ and 4-Mn. $\mathrm{M}=\mathrm{Mn}\left(\eta^{5}-\mathrm{C}_{5} \mathrm{H}_{4} \mathrm{Me}\right)(\mathrm{CO})$. 
Selectivity: A 9:1 mixture of 3-Mn : 3-Mn' is observed to form upon reaction of 2-Mn with CO. Hence, the pathway presented in Figure 4 cannot be the complete mechanistic picture. Based on the experimental findings, the mechanism towards the formation of 3-Mn' from 2-Mn was also investigated using DFT calculations (Figure 5). Isomerisation of 2-Mn was considered. A low-energy transition state TS-5 connects 2$\mathrm{Mn}$ with Int-4. This transition state involves migration of the aluminium fragment that is chelated by the isocarbonyl and $\mathrm{C}_{2}$ carbon chain from the $\mathrm{O}^{2}$ toward the $\mathrm{C}^{2}$ atom. The potential energy surface describing this reaction step is calculated to be reasonably flat and Int-4 is only $1.2 \mathrm{kcal} \mathrm{mol}^{-1}$ lower in energy than its associated TS-5. The low barrier to the reverse reaction suggests that the isomerisation of 2-Mn is reversible and by itself is not selectivity determining. Variable temperature ${ }^{1} \mathrm{H}$ NMR spectroscopy on $\mathrm{d}^{8}$-toluene solution of 2-Mn across a -60 to $+80^{\circ} \mathrm{C}$ range revealed a fluxional process involving at least one of the $\beta$-diketiminate ligands bound to aluminium. While the complexity of the data does not allow this process to be assigned to a specific molecular reorganisation, the observation is consistent with 2-Mn being unstable toward either isomerisation or conformational changes below $20^{\circ} \mathrm{C}$.

Subsequent rearrangement of Int-4 to Int-5 is calculated to be non-reversible and occurs via a single transition state TS-6. Like TS-5, TS-6 involves a migration of an aluminium fragment but this time from the $\mathrm{C}^{2}$ to the $\mathrm{O}^{2}$ atom of the carbon chain. The overall process from 2-Mn to Int-5 reorganises the molecular topology converting a $[7,4]$ fused ring system into a $[6,5]$ analogue. Insertion of the $C^{1} \equiv O^{1}$ isocarbonyl ligand into the $\mathrm{Mn}-\mathrm{C}^{2}$ bond of Int-5 results in the formation of Int-6, in which the [5,5] fused ring system structure of the product is set. Subsequent addition of CO forms 3-Mn'.

The calculations suggest that the isolated intermediate $\mathbf{2}-\mathbf{M n}$ provides a point of mechanistic divergence. The formation of 3-Mn and 3-Mn' are determined by TS-3 $\left(\Delta \mathrm{G}^{\ddagger}{ }_{298 \mathrm{~K}}=26.0 \mathrm{kcal} \mathrm{mol}{ }^{-1}\right)$ and TS-6 $\left(\Delta \mathrm{G}^{\ddagger}{ }_{298 \mathrm{~K}}=31.2 \mathrm{kcal}\right.$ $\mathrm{mol}^{-1}$ ) respectively. Although the relative energy barriers are consistent with the prediction of 3-Mn as the major product, closer comparison of the selectivity determining step reveals an energy difference beyond that predicted for a $9: 1$ mixture of products $\left(\Delta \Delta \mathrm{G}^{\ddagger}{ }_{298 \mathrm{~K}}=+5.2 \mathrm{kcal} \mathrm{mol}^{-1}\right)$, likely highlighting the accuracy of the DFT model. ${ }^{60}$ 


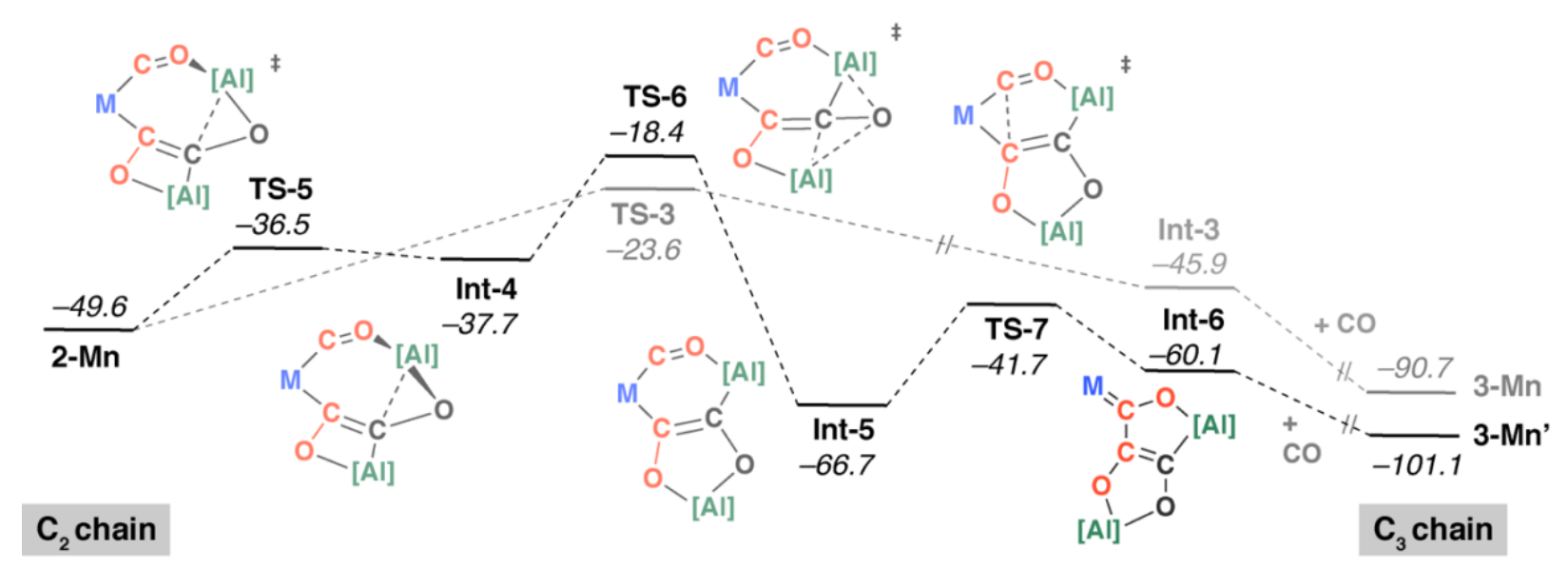

Figure 5. DFT calculated mechanism for the formation of 3-Mn' from 2-Mn. $M=M n\left(\eta^{5}-C_{5} H_{4} M e\right)(C O)$.

\section{Conclusions}

In summary, we have prepared a series of heterometallic products incorporating $C_{2}, C_{3}$ or $C_{4}$ chains derived from reaction of group 6-9 metal carbonyl complexes, $\mathrm{CO}$, and an aluminium(I) reductant. These reactions create rare polymetallic complexes in which a $\left\{\mathrm{C}_{n} \mathrm{O}_{n}\right\}^{4-}(\mathrm{n}=2-4)$ carbon chain is supported by both transition metal and main group centres. Electronic structures of a manganese series were interrogated by DFT calculations, showing that $C_{3}$ and $C_{4}$ products are best described as metallocarbene complexes of the transition metal. These calculations also suggest that the $\left\{\mathrm{C}_{n} \mathrm{O}_{n}\right\}^{4-}$ chain contains an alternating array of single and double bonds which is bonded to aluminium through polarised and largely ionic $\mathrm{Al}-\mathrm{O}$ and $\mathrm{Al}-\mathrm{C}$ bonds. Synthetic studies elucidated each of the steps in the reaction sequence $C_{2} \rightarrow C_{3} \rightarrow C_{4}$, confirming the $C_{2}$ product as intermediate in chain growth and showing the step from $C_{3}$ to $C_{4}$ chains is potentially reversible.

Modification of the electronics at the transition metal influences not only the relative rate of each chain growth step allowing but also the selectivity. Through modification of this component, the product distribution of the reaction can be tuned allowing access to different isomers of $C_{3}$ carbon chains which contain different topologies and different reactivity. Further calculations and isotopic labelling experiments were used to gain insight into the mechanism of chain growth. These studies suggest the reaction is initiated by an intermolecular attack of the nucleophilic aluminium(I) reagent at a transition metal carbonyl ligand. Chain growth then proceeds through a series of migratory insertion steps, occurring first at the transition metal site, then at the main group site. The selectivity that controls the chain topology, is influenced by the relative rates of migratory insertion and ligand reorganisation within the heterometallic framework.

In totality, this study provides unprecedented insight into the subtle mechanistic features (e.g. reversibility, selectivity, cooperative effects) involved in CO homologation in the presence of transition metal and main group centres. 


\section{Associated Content}

Supporting Information. X-ray crystallographic data for 2-4 are available from the Cambridge Crystallographic Data Centre (CCDC 2095244 - 2095254) and as a .cif file, full details of the experiments and calculations are available as a .pdf. Primary data (NMR, IR, and .xyz coordinates) can be downloaded from dx.doi.org/10.14469/hpc/8698.

\section{Author Information}

The authors declare no financial conflicts. Correspondence should be addressed to m.crimmin@imperial.ac.uk.

\section{$\underline{\text { Acknowledgements }}$}

We are grateful to the Royal Society for provision of a University Research Fellowship (MRC) and the ERC (FluoroFix: 677367) for generous funding. We thank Imperial College London for the award of a President's Scholarship (RYK). We also thank the EPSRC for project funding (EP/S036628/1).

\section{References}

(1) Zhou, W.; Cheng, K.; Kang, J.; Zhou, C.; Subramanian, V.; Zhang, Q.; Wang, Y. New Horizon in C1 Chemistry: Breaking the Selectivity Limitation in Transformation of Syngas and Hydrogenation of $\mathrm{CO}_{2}$ into Hydrocarbon Chemicals and Fuels. Chem. Soc. Rev. 2019, 48, 3193-3228.

(2) Ragauskas, A. J.; Williams, C. K.; Davison, B. H.; Britovsek, G.; Cairney, J.; Eckert, C. A.; Frederick, W. J.; Hallett, J. P.; Leak, D. J.; Liotta, C. L.; Mielenz, J. R.; Murphy, R.; Templer, R.; Tschaplinski, T. The Path Forward for Biofuels and Biomaterials. Science 2006, 311, 484-489.

(3) Ail, S. S.; Dasappa, S. Biomass to Liquid Transportation Fuel via Fischer Tropsch Synthesis Technology Review and Current Scenario. Renew. Sust. Energ. Rev. 2016, 58, 267-286.

(4) Anderson, R. B.; Friedel, R. A.; Storch, H. H. Fischer-Tropsch Reaction Mechanism Involving Stepwise Growth of Carbon Chain. J. Chem. Phys. 1951, 19, 313-319.

(5) West, N. M.; Miller, A. J. M.; Labinger, J. A.; Bercaw, J. E. Homogeneous Syngas Conversion. Coord. Chem. Rev. 2011, 255, 881-898.

(6) Kong, R. Y.; Crimmin, M. R. Cooperative Strategies for CO Homologation. Dalton Trans. 2020, 49, 16587-16597.

(7) Xu, M.; Qu, Z.; Grimme, S.; Stephan, D. W. Lithium Dicyclohexylamide in Transition-Metal-Free Fischer-Tropsch Chemistry. J. Am. Chem. Soc. 2021, 143, 634-638.

(8) Hu, S.; Shima, T.; Hou, Z. Hydrodeoxygenative Cyclotetramerization of Carbon Monoxide by a Trinuclear Titanium Polyhydride Complex. J. Am. Chem. Soc. 2020, 142, 19889-19894.

(9) Wang, B.; Luo, G.; Nishiura, M.; Luo, Y.; Hou, Z. Cooperative Trimerization of Carbon Monoxide by Lithium and Samarium Boryls. J. Am. Chem. Soc. 2017, 139, 16967-16973.

(10) Yadav, R.; Simler, T.; Gamer, M. T.; Köppe, R.; Roesky, P. W. Rhenium Is Different: CO Tetramerization Induced by a Divalent Lanthanide Complex in Rhenium Carbonyls. Chem. Commun. 2019, 55, 5765-5768. 
(11) Wang, Y.; Kostenko, A.; Hadlington, T. J.; Luecke, M.-P.; Yao, S.; Driess, M. Silicon-Mediated Selective Homo- and Heterocoupling of Carbon Monoxide. J. Am. Chem. Soc. 2019, 141, 626-634.

(12) Protchenko, A. V.; Vasko, P.; Do, D. C. H.; Hicks, J.; Fuentes, M. Á.; Jones, C.; Aldridge, S. Reduction of Carbon Oxides by an Acyclic Silylene: Reductive Coupling of CO. Angew. Chem., Int. Ed. 2019, 58, 1808-1812.

(13) Buss, J. A.; Bailey, G. A.; Oppenheim, J.; VanderVelde, D. G.; Goddard, W. A.; Agapie, T. CO Coupling Chemistry of a Terminal Mo Carbide: Sequential Addition of Proton, Hydride, and CO Releases Ethenone. J. Am. Chem. Soc. 2019, 141, 15664-15674.

(14) Buss, J. A.; Agapie, T. Four-Electron Deoxygenative Reductive Coupling of Carbon Monoxide at a Single Metal Site. Nature 2016, 529, 72-75.

(15) Buss, J. A.; Agapie, T. Mechanism of Molybdenum-Mediated Carbon Monoxide Deoxygenation and Coupling: Mono- and Dicarbyne Complexes Precede C-O Bond Cleavage and C-C Bond Formation. J. Am. Chem. Soc. 2016, 138, 16466-16477.

(16) Sharpe, H. R.; Geer, A. M.; Taylor, L. J.; Gridley, B. M.; Blundell, T. J.; Blake, A. J.; Davies, E. S.; Lewis, W.; McMaster, J.; Robinson, D.; Kays, D. L. Selective Reduction and Homologation of Carbon Monoxide by Organometallic Iron Complexes. Nat. Commun. 2018, 9, 3757.

(17) Deegan, M. M.; Peters, J. C. CO Reduction to CH3OSiMe3: Electrophile-Promoted Hydride Migration at a Single Fe Site. J. Am. Chem. Soc. 2017, 139, 2561-2564.

(18) Suess, D. L. M.; Peters, J. C. A CO-Derived Iron Dicarbyne That Releases Olefin upon Hydrogenation. J. Am. Chem. Soc. 2013, 135, 12580-12583.

(19) Majumdar, M.; Omlor, I.; Yildiz, C. B.; Azizoglu, A.; Huch, V.; Scheschkewitz, D. Reductive Cleavage of Carbon Monoxide by a Disilenide. Angew. Chem., Int. Ed. 2015, 54, 8746-8750.

(20) Braunschweig, H.; Dellermann, T.; Dewhurst, R. D.; Ewing, W. C.; Hammond, K.; Jimenez-Halla, J. O. C.; Kramer, T.; Krummenacher, I.; Mies, J.; Phukan, A. K.; Vargas, A. Metal-Free Binding and Coupling of Carbon Monoxide at a Boron-Boron Triple Bond. Nat. Chem. 2013, 5, 1025-1028.

(21) Gardner, B. M.; Stewart, J. C.; Davis, A. L.; McMaster, J.; Lewis, W.; Blake, A. J.; Liddle, S. T. Homologation and Functionalization of Carbon Monoxide by a Recyclable Uranium Complex. Proc. Natl. Acad. Sci. 2012, 109, 9265-9270.

(22) Arnold, P. L.; Turner, Z. R.; Bellabarba, R. M.; Tooze, R. P. Carbon Monoxide Coupling and Functionalisation at a Simple Uranium Coordination Complex. Chem. Sci. 2010, 2, 77-79.

(23) Miller, A. J. M.; Labinger, J. A.; Bercaw, J. E. Homogeneous CO Hydrogenation: Dihydrogen Activation Involves a Frustrated Lewis Pair Instead of a Platinum Complex. J. Am. Chem. Soc. 2010, 132, 33013303.

(24) Miller, A. J. M.; Labinger, J. A.; Bercaw, J. E. Homogeneous CO Hydrogenation: Ligand Effects on the Lewis Acid-Assisted Reductive Coupling of Carbon Monoxide. Organometallics 2010, 29, 4499-4516.

(25) Miller, A. J. M.; Labinger, J. A.; Bercaw, J. E. Reductive Coupling of Carbon Monoxide in a Rhenium Carbonyl Complex with Pendant Lewis Acids. J. Am. Chem. Soc. 2008, 130, 11874-11875.

(26) Watanabe, T.; Ishida, Y.; Matsuo, T.; Kawaguchi, H. Reductive Coupling of Six Carbon Monoxides by a Ditantalum Hydride Complex. J. Am. Chem. Soc. 2009, 131, 3474-3475.

(27) Evans, W. J.; Lee, D. S.; Ziller, J. W.; Kaltsoyannis, N. Trivalent $\left[\left(C_{5} M_{5}\right)_{2}(T H F) L n\right]_{2}\left(\mu-\eta^{2}: \eta^{2}-N_{2}\right)$ Complexes as Reducing Agents Including the Reductive Homologation of $\mathrm{CO}$ to a Ketene Carboxylate, $\left(\mu-\mathrm{H}_{4}-\mathrm{O}_{2} \mathrm{CCCO}\right)^{2-}$. J. Am. Chem. Soc. 2006, 128, 14176-14184.

(28) Evans, W. J.; Grate, J. W.; Hughes, L. A.; Zhang, H.; Atwood, J. L. Reductive Homologation of Carbon Monoxide to a Ketenecarboxylate by a Low-Valent Organolanthanide Complex: Synthesis and x-Ray Crystal Structure of $\left[\left(\mathrm{C}_{5} \mathrm{Me}_{5}\right)_{4} \mathrm{Sm}_{2}\left(\mathrm{O}_{2} \mathrm{CCCO}\right)(\mathrm{THF})\right]_{2}$. J. Am. Chem. Soc. 1985, 107, 3728-3730.

(29) Vrtis, R. N.; Lippard, S. J. Reductive Coupling of Carbon Monoxide and Alkyl Isocyanide Ligands in Early Transition Metal Complexes: A Review. Isr. J. Chem. 1990, 30, 331-341.

(30) Vrtis, R. N.; Rao, C. Pulla.; Warner, Steve.; Lippard, S. J. Carbynes Generated from Metal Carbonyl and Isocyanide Complexes; Intermediates in the Reductive Coupling of Carbonyl and CNR Ligands. J. Am. Chem. Soc. 1988, 110, 2669-2670.

(31) Bianconi, P. A.; Williams, I. D.; Engeler, M. P.; Lippard, S. J. Reductive Coupling of Two Carbon Monoxide Ligands to Form a Coordinated Alkyne. J. Am. Chem. Soc. 1986, 108, 311-313. 
(32) Neithamer, D. R.; LaPointe, R. E.; Wheeler, R. A.; Richeson, D. S.; Van Duyne, G. D.; Wolczanski, P. T.

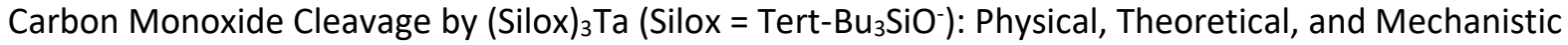
Investigations. J. Am. Chem. Soc. 1989, 111, 9056-9072.

(33) LaPointe, R. E.; Wolczanski, P. T.; Mitchell, J. F. Carbon Monoxide Cleavage by (Silox) ${ }_{3}$ Ta (Silox = Tert$\left.\mathrm{Bu}_{3} \mathrm{SiO}^{-}\right)$. J. Am. Chem. Soc. 1986, 108, 6382-6384.

(34) Summerscales, O. T.; Cloke, F. G. N.; Hitchcock, P. B.; Green, J. C.; Hazari, N. Reductive Cyclotrimerization of Carbon Monoxide to the Deltate Dianion by an Organometallic Uranium Complex. Science 2006, 311, 829-831.

(35) Summerscales, O. T.; Cloke, F. G. N.; Hitchcock, P. B.; Green, J. C.; Hazari, N. Reductive Cyclotetramerization of $\mathrm{CO}$ to Squarate by a U(III) Complex: The X-Ray Crystal Structure of [(U ( $\eta$ $\left.\left.\mathrm{C}_{8} \mathrm{H}_{6}\left\{\mathrm{Si}^{i} \mathrm{Pr}_{3}-1,4\right\}_{2}\right)\left(\eta-\mathrm{C}_{5} \mathrm{Me}_{4} \mathrm{H}\right)\right]_{2}\left(\mu-\eta^{2}: \eta^{2}-\mathrm{C}_{4} \mathrm{O}_{4}\right)$. J. Am. Chem. Soc. 2006, 128, 9602-9603.

(36) McKay, D.; Frey, A. S. P.; Green, J. C.; Cloke, F. G. N.; Maron, L. Computational Insight into the Reductive Oligomerisation of $\mathrm{CO}$ at Uranium(III) Mixed-Sandwich Complexes. Chem. Commun. 2012, 48, 4118-4120.

(37) Yuvaraj, K.; Douair, I.; Paparo, A.; Maron, L.; Jones, C. Reductive Trimerization of CO to the Deltate Dianion Using Activated Magnesium(I) Compounds. J. Am. Chem. Soc. 2019, 141, 8764-8768.

(38) Paparo, A.; Yuvaraj, K.; Matthews, A. J. R.; Douair, I.; Maron, L.; Jones, C. Reductive Hexamerization of CO Involving Cooperativity Between Magnesium(I) Reductants and [Mo(CO) 6 ]: Synthesis of WellDefined Magnesium Benzenehexolate Complexes. Angew. Chem., Int. Ed. 2021, 60, 630-634.

(39) Labinger, J. A. Approaches to Homogeneously Catalyzed CO Hydrogenation: A Personal Retrospective. J. Organomet. Chem. 2017, 847, 4-12.

(40) Nørskov, J. K.; Bligaard, T.; Rossmeisl, J.; Christensen, C. H. Towards the Computational Design of Solid Catalysts. Nat. Chem. 2009, 1, 37-46.

(41) Kong, R. Y.; Crimmin, M. R. Carbon Chain Growth by Sequential Reactions of $\mathrm{CO}$ and $\mathrm{CO}_{2}$ with $\left[\mathrm{W}(\mathrm{CO})_{6}\right]$ and an Aluminum(I) Reductant. J. Am. Chem. Soc. 2018, 140, 13614-13617.

(42) [AI] does not react with 1-Re under $\mathrm{N}_{2}$, and only reacts with 1-Re once $\mathrm{CO}$ is introduced into the reaction.

(43) Connor, J. A.; Jones, E. M.; Randall, E. W.; Rosenberg, E. The 13C Nuclear Magnetic Resonance Spectra of Carbene and Isonitrile Complexes of Chromium and Tungsten and a Reinvestigation of the $1 \mathrm{H}$ Nuclear Magnetic Resonance Spectra of Phenyl Carbene Complexes. J. Chem. Soc., Dalton Trans. 1972, No. 22, 2419-2424.

(44) Kreiter, C. G.; Formáček, V. Unusual 13C Chemical Shifts of Transition Metal-Carbene Complexes. Angew. Chem., Int. Ed. 1972, 11, 141-142.

(45) Bodner, G. M.; Kahl, S. B.; Bork, K.; Storhoff, B. N.; Wuller, J. E.; Todd, L. J. Carbon-13 Nuclear Magnetic Resonance Study of Carbenepentacarbonyl Complexes of Chromium(0) and Tungsten(0). Inorg. Chem. 1973, 12, 1071-1074.

(46) Cui, C.; Roesky, H. W.; Schmidt, H.-G.; Noltemeyer, M.; Hao, H.; Cimpoesu, F. Synthesis and Structure of a Monomeric Aluminum(I) Compound [ $\left.\left\{\mathrm{HC}(\mathrm{CMeNAr})_{2}\right\} \mathrm{Al}\right]\left(\mathrm{Ar}=2,6-\mathrm{IPr}_{2} \mathrm{C}_{6} \mathrm{H}_{3}\right)$ : A Stable Aluminum Analogue of a Carbene. Angew. Chem., Int. Ed. 2000, 39, 4274-4276.

(47) Frey, A. S.; Cloke, F. G. N.; Hitchcock, P. B.; Day, I. J.; Green, J. C.; Aitken, G. Mechanistic Studies on the Reductive Cyclooligomerisation of $\mathrm{CO}$ by U(III) Mixed Sandwich Complexes; the Molecular Structure of $\left[\left(U\left(\eta-\mathrm{C}_{8} \mathrm{H}_{6}\left\{\mathrm{Si}^{i} \mathrm{Pr}_{3}-1,4\right\}_{2}\right)\left(\eta-\mathrm{C} p^{*}\right)\right]_{2}\left(\mu-\eta^{1}: \eta^{1}-\mathrm{C}_{2} \mathrm{O}_{2}\right)\right.$. J. Am. Chem. Soc. 2008, 130, 13816-13817.

(48) Mills, O. S.; Redhouse, A. D. On the Existence of Metal Carbonyl Carbene Complexes. Angew. Chem., Int. Ed. 1965, 4, 1082-1082.

(49) Chai, J.-D.; Head-Gordon, M. Systematic Optimization of Long-Range Corrected Hybrid Density Functionals. J. Chem. Phys. 2008, 128, 084106.

(50) Zhao, Y.; Truhlar, D. G. The M06 Suite of Density Functionals for Main Group Thermochemistry, Thermochemical Kinetics, Noncovalent Interactions, Excited States, and Transition Elements: Two New Functionals and Systematic Testing of Four M06-Class Functionals and 12 Other Functionals. Theor. Chem. Acc. 2008, 120, 215-241.

(51) Grimme, S.; Antony, J.; Ehrlich, S.; Krieg, H. A Consistent and Accurate Ab Initio Parametrization of Density Functional Dispersion Correction (DFT-D) for the 94 Elements H-Pu. J. Chem. Phys. 2010, 132, 154104. 
(52) Tomasi, J.; Mennucci, B.; Cammi, R. Quantum Mechanical Continuum Solvation Models. Chem. Rev. 2005, 105, 2999-3094.

(53) Hooper, T. N.; Garçon, M.; White, A. J. P.; Crimmin, M. R. Room Temperature Catalytic CarbonHydrogen Bond Alumination of Unactivated Arenes: Mechanism and Selectivity. Chem. Sci. 2018, 9, 5435-5440.

(54) Alternative chain-initiation reactions were also considered. Attempts were made to model the nucleophilic attack of [AI] onto $\mathrm{CO}$, however no stationary point could be located. This finding supports experimental data as [Al] does not react with $\mathrm{CO}$ at $25^{\circ} \mathrm{C}$, nor could a reversible adduct be observed to form at $-80^{\circ} \mathrm{C}$ in VT NMR experiments.

(55) Experimentally, isolated heterometallic species containing $\mathrm{M}-[\mathrm{Al}]$ bonds including $\left[\mathrm{Cp}^{\prime} \mathrm{Mn}(\mathrm{CO})_{2}[\mathrm{Al}]\right]$ do not react with additional equivalents of $[\mathrm{AI}]$ and $\mathrm{CO}$ to form the chain-growth products. The data support the hypothesis that the attack of a transition-metal bound $\mathrm{CO}$ is the first step in chaingrowth.

(56) Li, X.; Ni, C.; Song, H.; Cui, C. Formation of Aluminacyclobutenes via Carbon Monoxide and Isocyanide Insertion. Chem. Commun. 2006, 0, 1763-1765.

(57) Kong, R. Y.; Crimmin, M. R. Reversible Insertion of $\mathrm{CO}$ into an Aluminium-Carbon Bond. Chem. Commun. 2019, 55, 6181-6184.

(58) Hartwig, J. F. Organotransition Metal Chemistry: From Bonding to Catalysis; University Science Books, 2010.

(59) A data-processing error resulted in an incorrect Gibbs' free energy for $\mathbf{4}-\mathbf{W}$ in our original communication. The correct energies are now reported in the $\mathrm{SI}$ and are consistent with $\mathrm{CO}$ insertion from $\mathbf{3}-\mathbf{W}$ to $\mathbf{4}-\mathbf{W}$ also being a reversible process.

(60) This computational model assumes facile trapping Int-3 with $\mathrm{CO}$. As such the $\mathrm{C}-\mathrm{C}$ bond forming step to generate 3-Mn is assumed to be non-reversible. In this scenario, selectivity is determined by the $\Delta \Delta \mathrm{G}^{\ddagger}$ of TS-3 and TS-6. If trapping of Int-3 with CO becomes slow, then C-C bond formation may become reversible. In this scenario selectivity, is potentially determined by not only the barrier heights but also the thermodynamic stability of Int-3 and Int-6. 